\title{
Variations
}

Variations

Revue internationale de théorie critique

16 | 2012

Tahrir is here !

\section{Prolonger Abensour : la désobéissance civile comme modalité de l'utopie}

\section{Manuel Cervera-Marzal}

\section{(2) OpenEdition}

Journals

Édition électronique

URL : http://journals.openedition.org/variations/163

DOI : 10.4000/variations. 163

ISSN : 1968-3960

Éditeur

Les amis de Variations

Édition imprimée

Date de publication : 16 janvier 2012

\section{Référence électronique}

Manuel Cervera-Marzal, «Prolonger Abensour : la désobéissance civile comme modalité de l'utopie », Variations [En ligne], 16 | 2012, mis en ligne le 20 février 2012, consulté le 19 avril 2019. URL : http:// journals.openedition.org/variations/163 ; DOI : 10.4000/variations.163

Ce document a été généré automatiquement le 19 avril 2019

Les ami•e•s de Variations 


\title{
Prolonger Abensour : la désobéissance civile comme modalité de l'utopie
}

\author{
Manuel Cervera-Marzal
}

\section{NOTE DE L'ÉDITEUR}

Première publication sur www.theoriecritique.com, « Tahrir is here ! », 16 janvier 2012, pp. 114-138

1 Nous souhaiterions ici examiner la relation entre désobéissance civile et utopie, en prolongeant les analyses de Miguel Abensour sur cette dernière notion ${ }^{1}$. Au niveau théorique, aucune connexion n'émerge de prime abord. Au niveau historique, cependant, il est remarquable que les désobéissants comptent parmi les plus productifs créateurs d'utopie. Gandhi le premier élabora, sous l'appellation de swaraj, un projet d'organisation du pouvoir où il serait réparti à la fois de bas en haut et du centre vers la périphérie, à la manière de cercles océaniques. La propension des désobéissants à l'utopie ne doit pas manquer de nous interroger. De même, le récent regain d'intérêt pour les pratiques désobéissantes et, simultanément, la réactivation de la notion d'utopie (à travers, notamment, le slogan altermondialiste d'un "autre monde possible ») sont peut-être davantage qu'une simple coïncidence. Nous faisons l'hypothèse que cette congruence socio-historique trouve son origine dans une affinité élective entre la désobéissance civile et l'utopie. Mieux encore, nous soutenons que la désobéissance civile constitue une modalité de la conversion utopique, une effectuation des potentialités émancipatrices et révolutionnaires de l'utopie, une « arme » de l'utopie contre l'ordre établi.

2 Pour démontrer cette hypothèse, il convient de procéder en trois temps. En nous référant aux travaux de Miguel Abensour, nous commencerons par présenter la notion d'utopie et par montrer en quoi elle constitue le nœud de la question de l'émancipation moderne (A/ ). Nous serons alors en mesure de traduire la désobéissance civile dans un langage philosophique, en vue de la redéfinir comme une modalité nouvelle - aux côtés de 
l'époché phénoménologique et de l'image dialectique - de la conversion utopique (B/). Une seconde option, non exclusive de la précédente, sera d'envisager la désobéissance comme une "arme » de l'utopie $(\mathrm{C} /$ ), en désignant par là l'ensemble des pratiques susceptibles d'éveiller les esprits endormis à «l'expression imaginative d'un monde nouveau ».

\section{A. Nouvel esprit utopique et émancipation moderne}

Dans le langage ordinaire, l'utopie n'augure rien de bon. On s'en méfie ou on en rit. Au mieux impossible, au pire dangereuse, elle a acquis une connotation exclusivement négative. Régulièrement prise pour bouc-émissaire, l'utopie porterait en germe la domination totalitaire. Du projet d'homme nouveau au goulag, le chemin est tout tracé, répètent les libéraux. De leur côté, les libertaires, pourtant si souvent taxés d'utopistes, n'en sont pas moins sévères à l'égard de l'utopie: bien qu'orienté vers la construction d'une société nouvelle, « l'anarchisme n'est pas utopique ! », assène Daniel Guérin. C'est ainsi l'ensemble du spectre politique qui, d'un commun accord, voue l'utopie aux gémonies.

Faut-il en conclure à un rejet définitif de l'utopie ? Dans le désert, une voix résiste, qui nous rappelle que l'évidente condamnation des totalitarismes n'est en aucune évidence assimilable à la condamnation des utopies. Depuis 1973, Miguel Abensour dénonce inlassablement cette identification hâtive et abusive entre utopie et totalitarisme ${ }^{3}$. La présupposition implicite de cette accusation réside dans l'idée erronée que l'utopie promouvrait l'avènement d'une société réconciliée et transparente à elle-même. «Or, c'est bien mal connaître l'utopie, car dans la diversité de ses traditions, on peut rencontrer des utopies où est soigneusement préservée la pluralité de la condition humaine, au point de conjurer le fantasme de la société homogène, chez Fourier par exemple $»^{4}$. Une analyse de l'idéologie national-socialiste ou de la politique stalinienne nous informe par ailleurs que les totalitarismes au pouvoir se sont empressés de liquider toutes idées - sur l'émancipation sexuelle ou l'éducation des enfants - qui pouvaient avoir un parfum d'utopie. Ainsi, Miguel Abensour renverse l'accusation, affirmant, sentencieux : «quand l'utopie décroît, le totalitarisme croît »5. Sa pensée sur ce point est en fait plus complexe. Mais, avant d'y revenir, arrêtons-nous sur l'origine et la définition de l'utopie.

Inventé par Thomas More dans l'ouvrage éponyme publié en 1516 à Louvain, le terme d'« utopie » désigne, en grec, le «nulle part », l'autre lieu qui n'est dans aucun lieu, l'ailleurs non identifié, «in-situable» ni dans le temps ni dans l'espace. L'utopie, chez More, a une fonction éminemment critique. Il s'agit de dénoncer l'état des choses existant dans l'Angleterre d'Henri VIII (corruption, désordre, schisme anglican), au nom d'une cité imaginaire organisée selon les principes de la raison et les exigences de la liberté. Prolongeant la réflexion de l'ami d'Erasme, Miguel Abensour définit l'utopie comme cette disposition qui grâce à un exercice de l'imagination ne redoute pas, dans une société donnée, d'en transcender les limites et de concevoir ce qui est différent, le tout autre social ${ }^{6}$. Demandons-nous, par exemple, en quoi pourrait consister l'utopie des intouchables indiens? Le tout autre social ne serait pas tant le renversement de l'ordre actuel - la soumission des brahmanes aux intouchables - que l'anéantissement pur et simple de sa logique hiérarchique - une société délivrée de l'archaïque système des castes. Autre exemple, l'utopie des sujets d'un Etat de droit pourrait résider dans 
l'avènement d'un monde où la loi ne serait plus fondée sur la contrainte physique mais sur la liberté de ceux à qui elle est destinée.

6 Nous avons vu plus haut comment Miguel Abensour, exaspéré par l'empressement des pourfendeurs de l'utopie, a pu formuler un rapport de proportionnalité inversé entre utopie et totalitarisme. Sa position est en réalité plus nuancée et plus complexe. Il convient de prendre en compte, avec tout le sérieux du monde, les critiques adressées par les adversaires de l'utopie. Une valorisation a-critique de l'utopie n'a en effet pas lieu d'être. Ainsi, "l'utopie ne saurait être, par volontarisme, d'emblée dissociée de la question du totalitarisme $»^{7}$. Il s'agit en quelque sorte d'accepter le dicton selon lequel « il n'y a pas de fumée sans feu ». Si certains ont déployé tant d'énergie contre l'utopie, on ne peut écarter d'un revers de la main l'ensemble de leurs réflexions. Par souci d'honnêteté intellectuelle, et par volonté de prévenir l'utopie de ses éventuelles dérives, il nous faut étudier les griefs qui lui ont été adressés. Car l'enjeu présent est précisément de prendre conscience que l'utopie peut fonctionner contre elle même. Elle porte en elle un risque d'autodestruction que nous ne devons aucunement nier. Miguel Abensour dénonçait le dénigrement systématique de l'utopie. Il faut éviter l'écueil opposé, à savoir un dogmatisme unilatéralement favorable à l'utopie. L'analyse doit procéder sans désenchantement, qui conduit à proclamer la fin de l'utopie, mais sans naïveté, qui conduit à des louanges aveugles. S'inspirant de l'école de Francfort, Abensour a défini d'une heureuse formule la «stratégie » à mettre en place: arracher aux ennemis de l'utopie les arguments contre l'utopie, pour les mettre au service de l'utopie'.

7 L'utopie n'est donc pas exempte de tout danger ; ce qui nous empêche de la dissocier trop rapidement de la question du totalitarisme. Mais, puisqu'utopie et totalitarisme ont donc un lien (qui n'est nullement de nature nécessaire), pourquoi ne pas, tout simplement, abandonner l'utopie aux oubliettes de la philosophie politique? Elle n'est certes pas le mal absolu, mais le simple fait qu'elle entretienne avec lui une relation, même ténue, pourrait nous conduire à vouloir rompre avec elle. Pourtant, cette voie n'est pas celle empruntée par Miguel Abensour. Pourquoi? Pour la raison toute simple que l'utopie est au centre du projet d'émancipation humaine. Le fait que l'émancipation moderne s'abreuve à la source de l'utopie nous enjoint de ne pas délaisser cette source mais bien plutôt de la purifier des bactéries totalitaires qui risquent toujours de germer en elle. « N'ayez pas peur, répète l'utopie. Ne fuyez pas. Purgez le mal qui est en moi car sans moi vous n'êtes rien ». Dès que l'on considère que la nature de l'homme est d'être libre, alors l'opération de sauvetage de l'utopie s'impose. Débarrasser l'utopie de son penchant totalitaire n'est pas une fantaisie mais un devoir. Il y a là un danger - car en pénétrant le champ de l'utopie on risque à chaque instant de glisser dans celui de la barbarie - que l'on prend non par goût du risque, mais par volonté que l'homme soit humain, c'est-à-dire qu'il soit libre. L'utopie est cette force qui fait advenir ce que Levinas appelle « l'élément humain ». Il est donc impératif de l'arracher à ses démons.

8 Mais quels sont ces démons de l'utopie ? La question de l'utopie se rapporte ici à celle, plus générale, de l'émancipation. L'enjeu est de comprendre l'échec du projet émancipateur moderne. L'école de Francfort et Miguel Abensour ont su pointer l'énigme à embrasser: la dialectique de l'émancipation, c'est-à-dire le mouvement paradoxal par lequel «l'émancipation moderne se retourne en son contraire, donne naissance à de nouvelles formes de domination et d'oppression - à la barbarie - et, ce en dépit de l'intentionnalité émancipatrice de départ $»^{9}$. Pour appréhender ce problème, Miguel Abensour propose de faire preuve d'un «nouvel esprit utopique $»^{10}$, dont la tâche serait 
de protéger l'utopie contre la régression qui la menace. Un tel travail ne peut s'effectuer qu'en deux temps.

9 Il s'agit d'abord de prendre conscience de la causalité interne du mal. Si l'émancipation et l'utopie qui la soutient peuvent se retourner en leur inverse - la barbarie totalitaire - cela est dû à l'impureté de leur nature propre. Il faut alors « cesser d'imputer ce retournement aux circonstances historiques » telles la guerre, la rareté, l'encerclement ${ }^{11}$. L'utopie doit reconnaître qu'elle est à elle-même sa première menace. De là découle la nécessité d'une autocritique. Ce second temps est celui du nouvel esprit utopique, qu'Abensour définit comme « présence au sein de la culture utopique d'un mouvement de soupçon à l'égard de l'utopie, d'autoréflexion, comme si l'utopie avait désormais intégré à sa démarche les arguments des ennemis de l'utopie, sans pour autant renoncer à sa visée première ni se résigner à proclamer la fin de l'utopie $»^{12}$. Quel est le contenu propre de cette autocritique? Comment l'utopie parvient-elle à conjurer ses démons ? Le mal qui la ronge de l'intérieur est celui du mythe de la société réconciliée et transparente à elle-même. Nous retrouvons ici l'image mythologique de l'âge d'or, du pays de Cocagne, du paradis sur terre, de la "bonne société » où les intérêts des uns s'accorderaient spontanément à ceux des autres et où les conflits entre personnes et entre groupes auraient définitivement disparu de ce monde. S'il y a des idées qui sont des crimes, alors celle-ci est la première d'entre elles. Car il y a dans ce fantasme de l'unité une négation de la vérité du politique qui est que, comme nous l'a enseigné Machiavel relu par Lefort, toute cité humaine s'institue à partir de la division, entre les grands et le peuple. La politique, loin de rejeter le conflit, en fait son fondement. Consubstantiel à la politique, le conflit doit être pensé comme insurmontable, non susceptible de s'éteindre. Le combat opposant le désir de dominer à celui de ne pas l'être est sans fin, et ne saurait nullement s'épuiser dans une résolution millénariste ou communiste de l'histoire. Il importe de purger l'utopie du mythe de l'extinction du politique, en rappelant que le conflit, inhérent au politique, est source de liberté.

10 Ainsi, à la question de départ, Abensour peut répondre qu'il faut imputer les effets potentiellement totalitaires de l'utopie à sa mythologisation. Seule une tradition utopique acceptant sans détour la dimension irrémédiablement agonistique du social-historique est susceptible de participer au processus d'émancipation moderne. Telle est la voie suivie par le «nouvel esprit utopique», et tel est le sens que nous donnerons au terme « utopie » dans la suite de notre propos.

11 Cependant, cette énigme résolue, l'utopie doit rester sur ses gardes. Un autre démon peut toujours surgir de nulle part - or l'utopie se définit comme le «nulle part » - et venir subvertir l'intention émancipatrice de l'utopie. Bien que libérée du mythe qui la minait, l'utopie doit rester attentive. L'émancipation n'est jamais un état, un donné, mais toujours un processus, au sens où la démocratie n'est rien d'autre que la démocratisation.

12 Nous venons ici de restituer le plus fidèlement possible la pensée de Miguel Abensour sur la notion d'utopie. Il nous faut désormais avancer d'un pas et voler de nos propres ailes. L'objectif des deux parties suivantes est d'étudier les liens que l'on peut nouer entre l'utopie abensourienne et la désobéissance civile, en sachant que le philosophe français n'a pas consacré la moindre ligne de son œuvre à ce concept. Cette comparaison nous semble doublement féconde, puisqu'elle permet d'envisager la désobéissance civile comme modalité de la conversion utopique d'une part (B/), et comme arme de l'utopie d'autre part (C/). 


\section{B. La désobéissance civile comme modalité de la conversion utopique}

13 Nous venons de voir que la tâche du nouvel esprit utopique, duquel Abensour se revendique, est de purger l'utopie du mythe de la société réconciliée. Mais pour purifier l'utopie, il faut d'abord s'y convertir, car le mal de l'utopie étant interne, on ne peut la soigner que de l'intérieur. Que désigne-t-on par conversion utopique ? Nous ne parlons pas ici d'une conversion au sens religieux. Il s'agit, explique Abensour, d'un mouvement, un déplacement, un processus dynamique par lequel l'homme se détourne de l'ordre ancien pour s'orienter vers « l'expression imaginative d'un monde nouveau » (Marx). Le rejet de l'ordre établi entraîne simultanément l'investissement pour l'édification de la société à venir.

Cette conversion s'effectue en deux phases indissociables. "D'abord, un moment philosophique, la reprise du doute cartésien, «doute partiel» et donc soumis à une extension radicale au point de donner naissance à un Doute absolu appliqué à la Civilisation, à sa nécessité, à son excellence et à sa personne. [...] Puis le moment proprement utopique en ce qu'il se déploie sous forme d'un mouvement d'Ecart absolu » ${ }^{13}$. La question devient alors celle du comment : Comment l'homme se convertit-il à l'utopie? Comment devient-il un animal utopique ? Répondre implique d'étudier une constellation de gestes, d'attitudes, d'affects, mais aussi, et surtout, d'élaborations philosophiques. Car, Miguel Abensour identifie deux modalités de la conversion utopique, qui relèvent toutes deux du plan philosophique: l'époché phénoménologique et l'image dialectique (par opposition à l'image mythologique) ${ }^{14}$.

Abensour n'écarte pas l'idée que puissent exister d'autres formes de conversion à l'utopie. Nous souhaiterions ici démontrer que la désobéissance civile est l'une d'elles. Mais une première difficulté apparaît alors immédiatement: la désobéissance civile désigne une pratique politique (en l'occurrence un mode d'action collective protestataire) alors que l'époché phénoménologique et l'image dialectique sont des élaborations philosophiques. Miguel Abensour, en choisissant ces deux concepts, semble implicitement suggérer que seule la philosophie peut fournir une explication satisfaisante au comment de la conversion utopique. Avant d'entreprendre la démonstration qui nous préoccupe (B/2.), nous voici donc contraint de traduire la désobéissance civile dans un langage philosophique (B/1.). En effet, étant donné que la conversion utopique est un geste philosophique, si l'on veut montrer que la désobéissance civile permet cette conversion, alors il faut penser la désobéissance sous sa forme philosophique. Cette difficulté n'handicape pas notre démonstration, car nous sommes en mesure de transposer la désobéissance dans le langage philosophique: l'idée de la servitude volontaire est la traduction philosophique de la désobéissance civile. Cette affirmation peut surprendre. Elle a donc besoin d'être étayée. Pour ce faire, montrons qu'à un triple niveau la désobéissance civile est le prolongement pratique de l'hypothèse philosophique de la servitude volontaire (B/1.). Nous verrons ensuite comment l'on peut définir le malencontre (dispositif central de la servitude volontaire) comme inversion utopique (B/2.). 


\section{De la servitude volontaire à la désobéissance civile} Discours de la servitude volontaire. La philosophie politique classique perçoit la domination comme le résultat de la puissance que les maîtres imposent à leurs sujets. Autrement dit, le tyran domine sa population car il est rusé et dispose des forces armées. La Boétie renverse cette perspective : les maîtres n'ont aucune capacité à instaurer la domination, ils ne sont pas rusés, et leur police est insuffisante pour asservir un peuple. La seule puissance des maîtres, c'est de leurs sujets qu'ils la tiennent. La domination n'est pas instaurée par le haut, mais par le bas. Les esclaves sont les propres auteurs de leur asservissement. Il n'existe de servitude que volontaire. servitude volontaire (a) et la prolongent vers ses conséquences pratiques: puisque l'obéissance aveugle rend servile, la désobéissance éclairée est émancipatrice (b) ; puisque le peuple s'assujettit lui-même, le peuple doit s'émanciper par son propre travail (c); puisque l'oppression est systémique, et nuit aux oppresseurs autant qu'aux oppressés, il faut se battre contre un système et non contre d'autres hommes (d).

\section{(a) La servitude volontaire} étonnement philosophique devant l'état de servitude à laquelle la majorité est réduite. Puis vient l'explication, qui se fonde sur une théorie du pouvoir comme consentement des sujets. Gandhi et Martin Luther King sont les héritiers de cette démarche intellectuelle.

Le Discours de la servitude volontaire part d'un étonnement philosophique, d'un fait proprement incompréhensible : l'état de servitude de la majorité : «Comm'il se peut faire que tant d'hommes, tant de bourgs, tant de villes, tant de nations endurent quelque fois un tyran seul, qui n'a de puissance que celle qu'ils luy donnent ; qui n'a de pouvoir de leur nuire, sinon tant qu'ils ont vouloir de l'endurer; qui ne scauroit leur faire mal aucun, sinon lors qu'ils aiment mieulx le souffrir que lui contredire $»^{15}$. Ainsi, pour Simone Weil, «la soumission du plus grand nombre au plus petit nombre, ce fait fondamental de presque toute organisation sociale, n'a pas fini d'étonner tout ceux qui réfléchissent un peu $»^{16}$. Gandhi est amené au même constat. En Inde, ce sont «cent mille Anglais » qui maintiennent l'exploitation coloniale de "trois cent millions d'êtres humains ${ }^{17}$. Sans aucun doute, cette servitude est un mal qu'il s'agit de combattre. Mais pour le combattre, il faut d'abord le comprendre. Il s'agit d'identifier la cause de la servitude.

Pour La Boétie, la seule puissance du tyran, c'est de ses sujets qu'il la tient. Et cela est d'autant plus surprenant que d'après le girondin, la nature humaine est liberté ${ }^{18}$. Il y a donc une contradiction surprenante entre la condition humaine (état de servitude) et la nature humaine (état de liberté). C'est à percer ce mystère de la domination que s'attache La Boétie. La perspective classique explique la domination en se centrant sur les maîtres actifs, manipulant leurs esclaves passifs grâce une large panoplie d'instruments: l'isolement des individus, le silence, la corruption et l'étourdissement, le divertissement, une fausse idée du devoir religieux et, en cas d'ultime nécessité, la force armée ${ }^{19}$. La révolution intellectuelle de La Boétie consiste à faire sensiblement bouger ces deux pôles ${ }^{20}$ : les esclaves deviennent actifs, et participent à cette domination. A la ruse des puissants 
qui trompent les esclaves, La Boétie substitue l'auto-tromperie des esclaves. On définit d'habitude la servitude comme une privation de liberté, qui provient d'une cause extérieure à celui qui subit l'assujettissement. Pourtant, lorsqu'il y a servitude volontaire, la cause de l'assujettissement n'est plus extérieure mais intérieure: "c'est le peuple qui s'asservit, qui se coupe la gorge $»^{21}$, écrit La Boétie. Le sujet se soumet volontairement au maître, il est l'auteur de sa servitude. Un peuple asservi ne l'est que parce qu'il l'a «choisi $»^{22}$.

Cette analyse de la nature du pouvoir était destinée à une belle descendance. Elle est reprise par Anselme Bellegarrigue qui, de manière assez sévère envers les opprimés, s'adresse à eux par les termes suivants : «Vous avez cru jusqu'à ce jour qu'il y avait des tyrans? Et bien! vous vous êtes trompés, il n'y a que des esclaves: là où nul n'obéit, personne ne commande $»^{23}$. Le dissident soviétique Vladimir Boukosky tire la même leçon de son expérience résistante: "Nous avons compris une grande vérité, à savoir que ce n'est pas le fusil, ce ne sont pas les chars, ce n'est pas la bombe atomique qui engendrent le pouvoir et le pouvoir ne repose pas sur eux. Le pouvoir naît de la docilité de l'homme, du fait qu'il accepte d'obéir ${ }^{24}$. Enfin, les millions d'euros que les armées occidentales investissent dans la recherche sur une stratégie de défense nationale fondée sur la noncoopération de masse prouvent que l'analyse laboétienne du pouvoir est pertinente aux yeux des dirigeants politiques actuels.

Gandhi reprend telle quelle l'hypothèse de la servitude volontaire puisqu'il reconnaît que «la servitude n'existe que parce qu'elle est volontaire $»^{25}$. En effet, d'après lui, «ce ne sont pas tant les fusils britanniques qui sont responsables de notre sujétion que notre propre coopération volontaire $\aleph^{26}$. Le gouvernement colonial n'a en lui aucun pouvoir puisqu'il « est impossible au gouvernement même le plus despotique de rester au pouvoir autrement qu'avec l'accord des gouvernés $»^{27}$.

Mais il faut maintenant prolonger l'analyse laboétienne pour nous demander comment les sujets manifestent leur volonté de servir. Dans les faits, comment s'exprime la servitude volontaire? Le désir de soumission, répond Pierre Clastres, prend forme dans "l'amour de la loi ${ }^{28}$ et l'obéissance aveugle au maître, c'est-à-dire aux lois qu'il édicte. La loi est la volonté du souverain sous sa forme juridique. Or il n'est pas de plus grande preuve d'amour du tyran que d'obéir à sa moindre volonté. « L'insuffisance d'amour, c'est la transgression de la loi $»^{29}$. Nous pouvons ainsi en conclure que l'obéissance inconditionnelle aux lois est le corollaire de la servitude volontaire.

\section{(b) La désobéissance émancipatrice}

24 Les penseurs de la désobéissance civile, s'étant basés sur l'hypothèse de la servitude volontaire, vont en tirer comme conséquence pratique la nécessité de désobéir au tyran pour précipiter sa chute.

Pour La Boétie, la liberté se confond avec le désir de liberté. Puisque le maître ne tient sa puissance que du don que les esclaves lui font de leur liberté, puisque le maître est à sa place uniquement parce que ses sujets l'y ont mis, il suffit à ces derniers de vouloir la liberté pour avoir la liberté ${ }^{30}:$ "soiés resolus de ne servir plus, et vous voilà libres ". Puisque la liberté est un attribut naturel des hommes, et qu'être libre et vouloir être libre ne font qu'un, le désir de liberté est donc lui aussi dans la nature de l'homme : « la nature de l'homme est bien d'estre franc et de le vouloir estre $»^{31}$. Il suffit donc aux sujets de cesser de soutenir leur maitre, leur tyran ou leur gouvernement pour que celui-ci 
périclite : "aussitôt que les sujets cessent de craindre la force du tyran, son pouvoir s'effondre $»^{32}$, affirme Gandhi. Ce constat permet d'élaborer une nouvelle méthode de lutte contre l'oppression du tyran: «Il ne faut pas que [...] nous restions complices, explique Gandhi. Au contraire, il faut combattre le mal en cessant d'apporter notre concours au malfaiteur d'une manière directe ou indirecte ${ }^{33}$. Or nous avons expliqué plus haut que le soutien au tyran se manifeste par l'obéissance inconditionnelle aux lois. Par conséquent, le combat contre ce mal doit commencer par le refus de l'obéissance inconditionnelle aux lois.

Le problème auquel nos penseurs sont parvenus peut être formulé ainsi : «comment anéantir un gouvernement qui nous oppresse, étant donné que ce gouvernement n'existe que parce que nous voulons qu'il existe, c'est-à-dire parce que nous obéissons systématiquement à ses lois?» La réponse est dans la question! Il n'est besoin ni d'insurrection ni de fusils, ni d'organisation secrète ni de partis. Nul besoin de sang, ni de brutalité. Nul besoin de lutter, il suffit de ne plus vouloir être esclaves. "Soyez donc résolus à ne plus servir et vous serez libres, déclare La Boétie. Je ne veux pas que vous le heurtiez, ni que vous l'ébranliez, mais seulement ne le souteniez plus, et vous le verrez, comme un grand colosse dont on dérobe la base, tomber de son propre poids et se briser " ${ }^{34}$. Il suffit aux sujets, pour faire chuter ce gouvernement, de cesser d'obéir inconditionnellement à ses lois. "Cela définit, en fait, une révolution pacifique " affirme Thoreau. Et il précise : «Quand le sujet a refusé obéissance et que le fonctionnaire démissionne, alors la révolution est accomplie ${ }^{36}$.

27 Cette nouvelle méthode, appelons-là, comme Thoreau, «désobéissance civile ${ }^{37}$. Cette stratégie d'action collective découle donc logiquement de l'idée philosophique de servitude volontaire. Thoreau ne fait que prolonger dans ses conséquences politiques et tactiques l'hypothèse de la servitude volontaire. Puisqu'un gouvernement ne tient que par le consentement de sa population, il suffit à cette dernière de retirer son aval pour faire chuter le gouvernement: "Aucun gouvernement, affirme Gandhi, et à plus forte raison le gouvernement indien, ne peut subsister si les gens cessent de le servir $\aleph^{38}$. De même, selon Thoreau, «si un millier d'hommes devaient s'abstenir de payer leurs impôts cette année ", cela suffirait à grever les recettes de l'Etat du Massachusetts et ainsi à l'empêcher " de commettre des violences et de verser le sang innocent " ${ }^{39}$ au Mexique.

28 Ainsi, la "puissance intrinsèque de l'acte $»^{40}$ de désobéissance civile découle de l'hypothèse philosophique de la servitude volontaire. Gandhi a parfaitement compris le lien inextricable entre ces deux théories, puisqu'il affirme : « en politique, son utilisation [l'utilisation de la désobéissance civile] est fondée sur la maxime immuable selon laquelle gouverner n'est possible que dans la mesure où la population consent, consciemment ou inconsciemment, à être gouvernée $»^{41}$. Mais l'héritage laboétien des penseurs de la désobéissance civile va plus loin. Ils doivent en effet à La Boétie d'avoir institué le peuple en acteur politique de sa propre émancipation.

\section{(c) L'auto-émancipation du peuple}

29 La Boétie opère un déplacement politique primordial : dans le jeu politique, le peuple n'est plus l'élément passif, dont le destin dépendrait uniquement de la volonté de Dieu et des décisions du roi. Désormais, le peuple est un acteur politique à part entière. Sa libération ne sera pas l'œuvre d'agents extérieurs. L'émancipation, pour être réelle, doit 
être une auto-émancipation. On retrouve cette idée au fondement de la notion de désobéissance civile.

Il faut parler, à propos de La Boétie, d'une véritable révolution intellectuelle. Après lui, il sera impossible de considérer le " peuple $»^{42}$ comme étant le sujet passif d'un maitre actif, rusé et manipulateur. La cause de la servitude est intérieure au peuple. Le tyran n'a aucune autre puissance que celle que lui fournissent ses sujets. Au maître, « il ne faut pas luy oster rien, mais ne lui donner rien $»^{43}$. L'oppression n'est pas le produit des maitres, faibles et efféminés, mais du peuple, seul capable de s'assujettir ou de s'émanciper.

Etant donné que la condition du peuple ne dépend que de son choix, le Discours «ne serait-il pas un appel à l'auto-émancipation du peuple? $»^{44}$, se demande, à juste titre, Miguel Abensour. La servitude volontaire est une idée qui fait proprement scandale. Et de nombreux oppresseurs du peuple pourraient la reprendre à leur compte, en arguant que si le peuple veut être servile, telle doit être sa condition. Mais la visée de La Boétie est inverse. Le jeune girondin pense la servitude volontaire depuis la liberté : puisque le peuple s'asservit, lui seul pourra se libérer, s'émanciper.

Il faut alors lire le Discours comme une œuvre éminemment politique et profondément engagée. C'est au peuple que revient la tâche de se libérer, et non à des agents extérieurs ou à des professionnels de la révolution qui, sous prétexte de lutte contre l'oppression, remplaceront les anciens tyrans par de nouveaux. L'histoire abonde d'exemples de révolutions manquées parce que menées et confisquées par une classe, un parti ou un homme. L'avant-garde révolutionnaire s'est bien souvent constituée en bureaucratie autoritaire réprimant dans le sang ce peuple au nom duquel elle avait pris le pouvoir. La Boétie n'a pas explicitement formulé la thèse de l'auto-émancipation. Mais tout chez lui l'annonce. Il faut donc considérer le jeune girondin comme l'annonciateur de la devise marxiste selon laquelle « l'émancipation des travailleurs doit être l'œuvre des travailleurs eux-mêmes ", et comme le pourfendeur de la doctrine léniniste des " professionnels de la révolution ", pour qui le prolétariat n'est rien sans l'avant-garde extérieure qui le guide et l'instruit.

Gandhi a constamment insisté sur la nécessité que la libération du peuple indien soit le résultat de sa propre action. A travers chacune des luttes qu'il a menées, le Mahatma s'est efforcé d'intégrer au combat les masses populaires. Aux yeux des nationalistes extrémistes, explique l'historien Claude Markovits, «la libération de l'Inde ne pouvait venir que de l'action d'une petite élite de héros affranchis de la peur physique du colonisateur. La masse du peuple, trop couarde pour se délivrer de la peur, devrait donc se tenir à l'écart et se contenter de soutenir et d'applaudir les héros dans leur lutte ${ }^{45}$. Gandhi, au contraire, proposa une technique « qui permettrait même à ceux qui n'étaient pas entraînés au combat physique de se délivrer de la peur et d'agir efficacement $»^{46}$. Le Mahatma fut ainsi le principal artisan de la transformation du Congrès en un parti politique de masse. Avant 1914, le Parti du Congrès ${ }^{47}$ n'était qu'un petit parti politique indien, composé d'une élite restreinte et anglicisée, faisant peu confiance à l'ensemble de la population, et menant seule des négociations timorées avec les Britanniques en vue d'une éventuelle indépendance lointaine. A partir de 1915 et de son retour définitif en Inde, Gandhi œuvre pour l'inclusion des masses dans le mouvement nationaliste et au sein du Congrès. Comme La Boétie, Gandhi pense que « le pouvoir vient du peuple $»^{48}$ et que c'est donc à lui, et non à une de ses fractions, de mettre un terme à l'oppression coloniale. Gandhi se méfie en fait de l'émergence d'une nouvelle élite qui mènerait seule le mouvement d'indépendance et qui, une fois les Anglais partis, monterait sur le trône de 
ces derniers. Il énonce là l'idée, centrale dans les mouvements d'indépendance, selon laquelle il est inutile de remplacer les exploiteurs coloniaux par des exploiteurs indigènes : « Si, en définitive, le seul changement attendu ne touche qu'à la couleur de l'uniforme militaire, nous n'avons vraiment pas besoin de faire toutes ces histoires. De toute façon, dans ce cas-là, on ne tient pas compte du peuple. On l'exploitera tout autant sinon plus, qu'en l'état actuel des choses $»^{49}$.

Se faisant l'exact écho de Gandhi, King affirme que le mouvement des droits civiques doit être l'œuvre de l'ensemble de la communauté noire. Dès le départ, il prend soin de choisir une forme de protestation permettant à tous les Noirs d'y participer. Ainsi, le 1er décembre 1955, suite à l'arrestation de Rosa Parks, une afro-américaine ayant refusé de laisser sa place à un Blanc dans le bus, King et ses collègues invitent les Noirs à n'utiliser aucun bus le 5 décembre suivant. Le choix du boycott est tout sauf anodin. Il permet aux enfants, aux femmes mais aussi «[aux] boiteux, [aux] estropiés et [aux] infirmes ${ }^{50}$ de prendre part au mouvement, et de se sentir pleinement intégrés dans la lutte que va mener, unie, toute une communauté d'opprimés. Durant ses quatorze années de vie publique, King veillera sans cesse à la dimension populaire du mouvement des droits civiques. Ainsi, à la veille de sa mort, pour la Campagne contre la pauvreté, King prévoit une " opération de désobéissance civile à grande échelle » qui inclura " tous les pauvres » 51 .

35 L'auto-émancipation du peuple ne doit pas se tromper d'adversaire : les théoriciens de la désobéissance civile cherchent à éradiquer le mal à la sa racine.

\section{(d) Lutter contre un système}

36 Il convient de remarquer qu'une troisième et dernière composante de l'hypothèse laboétienne de la servitude volontaire est reprise (et prolongée politiquement) dans la pratique désobéissante de Gandhi et de King : la source du mal réside dans un système moins que dans les individus, qui doivent être considérés comme les rouages de ce système.

Lorsque, dans le Discours de la servitude volontaire, La Boétie parle de " tyrannie », il entend par là une structure sociale pyramidale, formée d'oppression généralisée des individus supérieurs sur les individus inférieurs. La tyrannie est un système saturé de hiérarchie. Le premier tyran, situé au sommet de la pyramide d'oppressions, est soutenu par « quatre ou cinq $»^{52}$ hommes. Ces quatre ou cinq se dévouent au confort du tyran et acceptent de souffrir pour obtenir ses faveurs. S'ils s'abaissent ainsi, c'est qu'en compensation ils « en ont sous eux six cent qu'ils dressent, qu'ils corrompent aussi comme ils ont corrompu le tyran. Ces six cent en tiennent sous leur dépendance six mille $»^{53}$ à qui ils octroient quelques privilèges, et ainsi de suite jusqu'à la base de la pyramide. La société est donc entièrement infestée de "petits tyranneaux» oppressés par leurs supérieurs et oppressant leurs inférieurs. Dans un tel état social, l'amitié est impensable et le bonheur chimérique. L'amitié n'est en effet possible "qu'entre gens de bien", non entre tyranneaux. Les méchants, quant ils s'assemblent, "ne sont pas amis, mais ils sont complices ", écrit La Boétie ${ }^{54}$. En outre, chaque seconde de vie est employée à plaire à un supérieur qui fait régner son arbitraire, et à éviter que les inférieurs que l'on exploite ne se vengent et ne nous tuent ${ }^{55}$. Dans ces conditions, le bonheur n'est pas permis ${ }^{56}$.

Cette analyse du social peut être dite systémique, au sens où les individus sont pris dans un système ${ }^{57}$ qui les dépasse et les maîtrise. Ils sont certes les auteurs de ce système - ce 
système n'est pas né de nulle part, il est une construction humaine, et les hommes en portent la responsabilité - mais, une fois ce système mis en place, les individus en deviennent des pièces et des rouages ayant perdu leur autonomie et ne parvenant pas à s'en extraire ${ }^{58}$.

Cette analyse «systémique» du pouvoir a une influence considérable sur le choix de l'action politique qui va être employée pour abattre la tyrannie. Le remède dépend en effet du diagnostic. Si l'on pense par exemple que le mal réside dans la seule personne du tyran, on sera alors favorable au tyrannicide ou à la propagande par le fait (attentats contre les dirigeants politiques). Au contraire, les penseurs de la désobéissance civile optent, comme La Boétie, pour une analyse systémique : le mal réside dans un système. Ainsi, King se réjouit qu'en 1963 à Montgomery, les militants du mouvement aient compris que «l'ennemi du Noir n'était [pas] un individu, mais un système qui amenait celui-ci à mal agir $»^{59}$.

L'analyse systémique a donc pour première conséquence d'atténuer la responsabilité des oppresseurs. La deuxième conséquence, liée à la précédente, est que les opprimés ont pour ennemi un système et non d'autres être humains. «En faisant appel à la méthode non-violente, affirme Gandhi, c'est le capitalisme et non le capitaliste que nous cherchons à détruire $»^{60}$. Selon lui, il faut s'opposer et détruire les «systèmes» et non leurs "auteurs ${ }^{61}$. Enfin, la troisième conséquence de l'analyse systémique est que les oppresseurs pâtissent autant de l'oppression que les opprimés. King explique ainsi que « la ségrégation est un mal parce qu'elle s'attaque à l'âme de l'un et de l'autre, à l'âme de celui qui soutient la ségrégation et à sa victime. Le Noir n'est pas le seul qui souffre, la nation toute entière en souffre $\|^{62}$. Une telle affirmation n'est pas purement métaphysique. King explique en effet que «beaucoup de Blancs déshérités furent des victimes au second degré de l'esclavage $»^{63}$. De fait, la présence de millions d'esclaves sur le continent américain a "complètement faussé » le prix du travail et a maintenu les salaires des ouvriers blancs à un niveau extrêmement bas. Et King va jusqu'à inverser notre vision traditionnelle de la victime puisque, parlant toujours des travailleurs blancs, il affirme qu'« en un sens, leur condition est pire que celle des Noirs, car ils ont été tellement abusés par les préjugés qu'ils en sont arrivés à soutenir leurs oppresseurs ${ }^{64}$. Gandhi, à l'instar de King, plaide pour la compassion envers les oppresseurs, perçus comme les premières victimes de leur propre système. Comme le dit Ashish Nandy, «toute sa vie, Gandhi a cherché à libérer les Anglais plus que les Indiens du système esclavagiste, et à libérer les Brahmanes plus que les Intouchables du système des castes " ${ }^{65}$. En abordant l'oppresseur avec les yeux du philosophe "systémicien », on ne peut voir en lui qu'un homme malheureux et perdu, qui commet le mal non par méchanceté mais par désespoir. En conséquence, au moment de la révolte, il faut traiter le tyran non seulement comme un homme - avec le respect que l'on doit à tout homme - mais aussi comme un être perdu, à qui il faut apporter le réconfort. Gandhi et King souscriraient ainsi sans hésiter aux propos de Barthélémy de Ligt, pour qui «un véritable révolutionnaire ne peut jamais être ennemi envers ses ennemis ni criminel envers des criminels, et d'autant moins parce que les criminels sont en premier lieu des victimes de la société. La révolution exige non seulement le renoncement de toute violence vis-à-vis des peuples et des classes, mais aussi vis-à-vis des individus " ${ }^{66}$.

41 Nous achevons ainsi la traduction philosophique de la désobéissance civile en servitude volontaire. Mais un point, crucial pour la suite de notre développement, doit être l'objet de notre attention : si la servitude volontaire est bien le reflet de la désobéissance civile à 
travers le miroir de la philosophie, ce reflet - comme tout reflet - est inversé! Un miroir inverse toujours l'image du visage qui se place face à lui. La gauche devient la droite, et la droite devient la gauche. De même, la servitude volontaire, en reflétant la désobéissance civile, procède à son inversion. En effet, comme nous l'avons expliqué plus haut (cf. $\mathrm{B} / 1$.c.), la servitude volontaire formule en négatif (les dominés s'auto-asservissent) ce que la désobéissance civile exprime positivement (les dominés s'auto-émancipent). Cette réflexion sur le reflet inversé nous servira à la fin de la partie suivante (B/2.). Il s'agit désormais d'envisager le rapport de l'hypothèse laboétienne à la notion de conversion utopique. Ayant démontré l'unité de la servitude volontaire et de la désobéissance civile, la comparaison de la servitude volontaire et de l'utopie dévoilera indirectement la nature du rapport entre désobéissance civile et utopie.

\section{Le malencontre comme « inversion utopique »}

L'étonnement philosophique de La Boétie repose sur le constat de la surprenante contradiction entre la nature humaine (qui est état de liberté) et la condition humaine (qui est état de servitude). Partant, le Discours s'articule autour de deux questions : 1. Comment est-on passé de la liberté à la servitude, du premier stade au second ? 2. Comment se perpétue la servitude, comment les hommes persévèrent-ils dans ce second stade? Pierre Clastre ${ }^{67}$ a reformulé cette double interrogation en termes modernes: 1 . Pourquoi la division dominants/dominés s'est installée dans la société ? 2. Comment cette division se perpétue au point d'en paraître éternelle? Ou encore: 1. L'origine de la division sociale, de la domination, de l'Etat. 2. La perpétuation de la division sociale, de la domination, de l'Etat. La Boétie répond à la seconde question. Premièrement, le maître maintient sa domination grâce à un ensemble de quatre instruments : l'isolement des individus, le silence, la corruption et l'étourdissement, une fausse idée du devoir religieux et, en cas d'ultime nécessité, la force armée ${ }^{68}$. Deuxièmement, puisqu'on "ne regrette jamais ce qu'on n'a jamais eu», le peuple ne cherche pas à reconquérir sa liberté originelle et se complaît dans son assujettissement. En effet, la première cause de la servitude, c'est l'habitude, la "coustume $»^{69}$. L'énigme du Discours réside ainsi dans la première des deux questions : le passage, la transition, le basculement du peuple de l'état de liberté - correspondant à la nature humaine - à l'état de servitude - constaté empiriquement. "Quel mal encontre a esté cela, qui a peu de tant de naturer l'homme, seul né de vrai pour vivre franchement; et lui faire perdre la souvenance de son premier estre, et le désir de le reprendre? $\gg^{70}$ Malencontre : instant de basculement, qui fait passer une société de la liberté à la servitude. En termes modernes, nous dirions « origine de l'État ".

Ainsi défini, qu'est-ce que le malencontre sinon l'exact opposé de la conversion utopique qui, rappelons-le, désigne le passage de la désaffection pour l'ordre existant au nouvel investissement pour la société future. Le sujet converti fait l'expérience d'un "véritable décollage ». La conversion s'entend comme projection vers un au-delà visible mais non identifiable. Le sujet de la conversion, au moment où il en fait l'épreuve, se définit comme pro-jet: détaché de toute détermination préalable dans laquelle l'enfermerait l'ordre établi (la topie), le converti décolle vers l'au-delà, se pro-jette vers l'u-topie (l'autre topie). Affranchi des conditionnements de tout ordre (économique, social, familial, historique, psychologique, etc), le converti n'est rien d'autre que ce qu'il se pense. Plus précisément, il n'est rien d'autre que ce qu'il s'imagine, car l'opérateur de l'utopie est 
l'imagination. Cette conversion, en tant qu'elle projette vers l'utopie émancipatrice, est donc une progression. Le malencontre, à l'inverse, doit être envisagé comme régression. Cette chute de l'état de liberté à celui de servitude correspond à la substitution d'une structure sociopolitique à une autre : le Tous Un écarte et remplace le Tous uns.

Le Tous uns est le mode d'institution politique du social conforme à la nature humaine : « la nature a monstré en toutes choses qu'elle ne vouloit pas tant nous faire tous unis que tous uns ", écrit La Boétie ${ }^{71}$. Il s'articule autour de trois caractéristiques: le pouvoir politique est immanent à la société, il repose sur le fait irréductible de la pluralité humaine, et il vise la liberté des hommes. Le malencontre fait advenir le Tous Un, où le pouvoir est désormais séparé de la société, entre les mains d'Un seul (qui exerce son charme sur les autres), et orienté vers une totalité unitaire. A quoi correspondent historiquement ces deux formes d'institution politique du social? Le Tous uns, à rien. Jamais homme n'a vécu sous un tel régime, à moins de verser dans un idéalisme naïf qui consiste à voir dans de brèves expériences comme la Commune de Paris ou la Catalogne anarchiste des sociétés "parfaites» et idéales ${ }^{72}$. Etant donné que le Tous uns est historiquement étranger à la modernité politique d'une part, et qu'il est par définition le lieu du respect de la nature, de la liberté et de la pluralité humaines d'autre part, nous pouvons dire qu'il s'agit stricto sensu d'une utopie. Le Tous Un, au contraire, entre parfaitement dans la catégorie de "topie»: il s'est historiquement incarné lors des expériences totalitaires, et il constitue la négation de l'humain et l'éviction du politique.

La transition entre ces deux modes d'organisation sociopolitique s'effectue parallèlement à la dénaturation de l'homme. Malencontre et dénaturation constituent les deux faces d'un même phénomène. Autrement dit, la logique de régression se manifeste sur deux plans distincts mais intimement liés: au passage du Tous uns au Tous Un (malencontre) correspond cet incroyable et malheureux événement que La Boétie nomme dénaturation de l'homme, c'est-à-dire perte de sa liberté. Son changement de nature est une régression puisqu'il prend la forme d'une chute de l'humanité vers l'animalité. L'homme dénaturé a perdu sa liberté, et jusqu'au désir même de la reprendre. Cet état est donc destiné à durer 73 .

Nous avons vu plus haut (cf. point 1.) comment la conversion utopique - purgée de la mythologie - projette son sujet de la topie (domination) à l'utopie (émancipation). Le malencontre emprunte le même trajet (topie-utopie), mais en sens inverse (du Tous uns vers le Tous Un, c'est-à-dire de l'utopie vers la topie). Face à la troublante symétrie du malencontre (qui est régression) et de la conversion utopique (qui est progression), nous proposons ici la notion d'inversion utopique pour désigner la dynamique de régression propre au malencontre. L'inversion utopique est davantage qu'une simple inversion car, comme l'indique la charge de radicalité attachée à l'adjectif « utopique », le malencontre ne désigne pas uniquement la perte de la liberté : il en va, bien plus profondément, de la perte du désir même d'être libre.

Pour mieux cerner l'essence de l'inversion utopique, deux précisions s'imposent. Tout d'abord, le malencontre est un événement historique qui est fortuit, "sans nécessité ", «accidentel $»^{74}$. Etant pure contingence, aucune science de l'homme ne pourra, en définitive, fournir clairement les raisons de l'avènement du malencontre. Il s'agit là du nœud gordien de l'énigme du Discours, et donner une explication à la dénaturation de l'homme reviendrait à trahir la pensée de La Boétie. En conséquence, le malencontre est un basculement soudain. Il instaure la servitude, l'introduit pour la première fois dans la 
société humaine. Et ce n'est que dans un second temps que la coutume et l'habitude interviennent, pour faire perdurer le règne de la domination.

Rassemblons maintenant les pièces de notre puzzle. Nous avons montré ce qui suit :

1. l'hypothèse de la servitude volontaire est la traduction, dans un langage philosophique, de la désobéissance civile

2. cette traduction opère un "effet miroir ", c'est-à-dire que la servitude volontaire exprime en négatif ce que la désobéissance civile réalise positivement

3. la vérité de la servitude volontaire réside dans la soudaineté du malencontre

4. le malencontre constitue une inversion utopique (définie comme le trajet opposé de la conversion utopique).

Sous forme d'équations, les quatre affirmations précédentes donnent :

1. « désobéissance civile » = - « servitude volontaire »

2. « servitude volontaire $»=$ « malencontre »

3. «malencontre» = «inversion utopique », or «inversion utopique » = - « conversion utopique », donc « malencontre » = - « conversion utopique »

Nous en déduisons que :

1. « désobéissance civile » = - « servitude volontaire »

2. « servitude volontaire » = - « conversion utopique » préoccupe aussi d'identifier les « armes » de l'utopie. Parmi elles, la révolution bien sûr, «qui réactive les rêves du collectif qui peuplaient le sommeil des dominés et des exploités $»^{76}$, mais aussi les « laboratoires d'utopie » (Ronald Creagh) - ces pratiques des petits groupes qui travaillent à faire renaître le lien social dans le dos de l'Etat (communautés paysannes autogérées, coopératives ouvrières, etc). Là encore, Abensour laisse la porte ouverte au repérage et à l'édification d'autres ressources utopiques. L'utopie a pour visée de nous extraire du dogmatisme froid du réalisme, qui laisse croire aux dominés qu'ils sont condamnés à vivre dans le monde où ils vivent ${ }^{77}$. L'utopie nous agrippe, nous secoue, nous arrache à ce dogme pour éveiller en nous la conscience qu'un autre monde est à la fois possible et souhaitable (C/1.). La désobéissance civile, en tant que technique de l'éveil, constitue ainsi une autre arme de l'utopie (C/2.).

\section{L'éveil utopique}

L'utopie remplit sa double fonction critique (doute absolu appliqué à la Civilisation) et créatrice (expression imaginative d'un monde nouveau) au moyen d'une technique de l' 
éveil. La puissance d'éveil de l'utopie ${ }^{78}$ réside dans sa capacité à arracher le dormeur à son sommeil et aux "illusions nécessaires $»^{79}$ de la nuit qui, pour se maintenir, œuvre à produire un consentement aveugle quant au bienfondé de son existence. Cette métaphore nous semble particulièrement féconde. L'éveil, synonyme de réveil, désigne le passage de l'état de sommeil à l'état de veille, du rêve à la réalité, de l'onirisme au réalisme, de l'imaginaire au réel. Cette transition advient soudainement mais dure suffisamment longtemps pour que durant l'intervalle entre sommeil et veille le sujet puisse exercer simultanément son imagination nocturne et sa raison diurne ${ }^{80}$.

Le génie de l'utopie réside dans cette combinaison entre la puissance créatrice de l'imagination et le savoir analytique de la raison. Car, comme l'écrit Cornelius Castoriadis, «accepter que rationalité et imagination s'excluent l'une l'autre, c'est ne rien avoir compris à l'une et à l'autre $»^{81}$. En effet, le rêve lorsqu'il est seul fait plonger l'utopie dans les méandres du mythe, dont nous avons déjà pointé les dangers totalitaires. De même, la raison, seule, n'est que l'instrument du froid dogmatisme de l'ordre établi. Le sommeil est une absence d'action sur le réel. Or cette passivité, qui se veut neutralité, est en réalité complicité, au sens où «ne rien faire, c'est laisser faire ». En politique, se retirer c'est cautionner l'ordre existant. Ainsi, le retrait dans le sommeil est coupable. Mais l'état de veille n'est pas davantage utopique et louable. Car veiller, c'est administrer la réalité à partir des critères qui lui sont propres. La veille est une gestion froide et technicienne du réel, fondée sur le principe d'efficacité et la culture du résultat. Elle opère ainsi une réduction du possible au réel. Seul le réveil est utopique, car il est à la fois action sur le réel, mais une action non technicienne puisqu'orientée par l'imagination nocturne, qui ouvre l'éventail des possibles.

L'éveil, en tant que passage et qu'intervalle du sommeil à l'état de veille, permet de purifier l'un par l'autre et de ne garder de chacun que ce qu'il recèle de meilleur. Le souci du réel (lucidité) propre à l'état de veille tempère les ardeurs de l'imagination nocturne pour l'empêcher de glisser vers le mythe totalitaire de l'âge d'or. A l'inverse, la créativité onirique permet au réalisme d'éviter l'écueil du fatalisme et de s'ouvrir aux multiples futuribles. Ainsi, l'utopie n'est pas le rêve; tout comme il est évident qu'elle n'est pas le réel. Son pouvoir d'éveil prend sa source dans une articulation, une pondération réciproque de la nuit et du jour.

Comme l'a montré Miguel Abensour, l'originalité théorique de Thomas More est d'avoir conçu une «technique du réveil »: en Utopie, il procède à une diminution sensible de la journée de travail ramenée à six heures. Cette réduction du temps de travail est un éveil à l'utopie parce que le travail est le meilleur lieu d'intériorisation de l'ordre établi et de sa prétendue inéluctabilité. Dans $L a$ condition ouvrière, Simone Weil raconte la paralysie intellectuelle infligée par les heures passées à l'usine. La fatigue physique fait obstacle à l'exercice de la raison et de l'imagination critiques. «La percée utopique de Thomas More est d'avoir compris qu'il fallait travailler moins pour rêver plus $»^{82}$, écrit Abensour. Si nous souscrivons pleinement à cette analyse de la réduction de la journée de travail comme technique du réveil, nous pensons cependant qu'il faudrait peut-être manifester moins d'enthousiasme à l'égard de la technique du maintien de la veille que l'on trouve chez More, à savoir l'étude des lettres. La veille et ce qui permet de la maintenir - l'étude et l'acquisition du savoir livresque - sont valorisées à tort, nous semble-t-il, par Thomas More et, dans une certaine mesure, par Miguel Abensour.

En insistant constamment sur la vertu de la réflexivité et sur la nécessité de l'autocritique utopique, Miguel Abensour invite ses successeurs à ne pas arrêter leur réflexion devant 
une prétendue autorité intellectuelle, fût-ce Miguel Abensour lui-même. Aussi souhaitons-nous maintenant procéder à une critique d'Abensour (refus de la veille), par Abensour (au nom de la démocratie insurgeante en tant qu'« entre-deux »), pour Abensour (sauver l'utopie) $^{83}$. On peut, nous semble-t-il, associer la notion d'éveil à celle de "démocratie insurgeante", étant donné que, dans les deux cas, est désignée une dynamique de la subversion, une rupture avec l'ancien état des choses, bref, une impulsion émancipatrice. Or, dans La démocratie contre l'Etat, Abensour insiste sur le fait que la démocratie insurgeante s'inscrit dans une temporalité de la "césure ». Elle se manifeste comme un entre-deux, "c'est-à-dire entre la fin d'un régime et l'apparition d'une nouvelle forme étatique. Elle lutte donc sur deux fronts: contre 1' «Ancien Régime » en voie de disparition, et contre l'Etat nouveau qui souhaite le remplacer ${ }^{84}$. La démocratie insurgeante œuvre à maintenir cet entre-deux. Dans cette perspective, ne devrait-on pas aussi circonscrire l'éveil utopique dans une temporalité de l'entre-deux ? L'éveil, passage de l'état de sommeil à celui de veille, ne serait-il pas le temps exclusif de l'utopie, au point qu'il nous faudrait congédier le moment de la veille, comme nous l'avons fait pour celui du sommeil ? Car, à bien y regarder, la description de l'île d'Utopie par l'explorateur Raphaël Hythlodée présente de nombreux traits de l'âge d'or : société parfaitement égalitaire, organisée conformément aux lois de raison. Outre la parenté totalitaire du mythe de l'âge d'or et de la société transparente à elle-même, déjà exposée par Miguel Abensour, ne peut-on pas ajouter que l'âge d'or est un âge qui dort ? La veille, en tant qu'elle laisse irrémédiablement s'installer la fatigue au cours de la journée, conduit aux ténèbres du sommeil. Le jour annonce déjà la nuit. Ainsi, plutôt que d'opposer les vertueux rayons de la veille à la vicieuse pénombre du sommeil, tel que le fait Thomas More, il conviendrait de dépasser les apparences pour s'apercevoir que le jour et la nuit constituent finalement deux formes complémentaires d'un même projet: l'extinction du réveil utopique. Exprimés en termes politiques, le di-urne et le noct-urne, en tant que passages par l'urne, s'incarnent dans le régime de la démocratie élective et représentative. Or en politique, la représentation est dépossession. Donc diurne et nocturne s'opposent conjointement à une "démocratie véritable " telle que pourrait l'envisager une utopie, par exemple socialiste.

60 Une autre considération vient conforter l'hypothèse de la nature dystopique (contreutopique) de la veille. Rappelons que chez Thomas More, la technique du maintien de la veille est celle de l'étude des lettres: "Chacun est libre d'occuper à sa guise les heures comprises entre le travail, le sommeil et les repas - non pour les gâcher dans les excès et la paresse, mais afin que tous, libérés de leur métier, puissent s'adonner à quelque bonne occupation de leur choix. La plupart consacre ces heures de loisir à l'étude. Chaque jour en effet des leçons accessibles à tous ont lieu avant le début du jour, obligatoires pour ceux-là seulement qui ont été personnellement destinés aux lettres. Mais, venus de toutes les professions, hommes et femmes y affluent librement, chacun choisissant la branche d'enseignement qui convient le mieux à sa forme d'esprit ${ }^{85}$. Les Utopiens sont donc des êtres d'étude. Nous pourrions avec bienveillance nous extasier devant cette société où l'accès aux lettres serait libre, égal et universel. Mais il est tout aussi valable de s'en inquiéter, car cette valorisation acritique des études ne conduit-elle pas à adopter de nouveau la posture platonicienne qui fait prévaloir la théorie sur l'action? Or, comme l'expliquait Arendt, ce primat de la vita contemplativa sur la vita activa conduit à subordonner la délibération et l'action politiques à l'étalon supérieur de la vérité - vérité dont les seuls détenteurs seront les Utopiens savants, à savoir ceux destinés aux études et ceux qui, par goût, y consacreront leurs heures de loisir. On retomberait alors dans le 
primat du sage sur les insensés, du savant sur les hommes ordinaires, primat qui débouche sur une société entièrement subordonnée au philosophe-roi. Le modèle d'organisation sociopolitique auquel nous aboutissons se dénote par son caractère hautement antidémocratique, qui le rend incompatible avec l'exigence égalitaire de l'utopie. Entendons-nous bien. Il ne s'agit pas ici de rejeter en bloc tout savoir livresque, au motif qu'il accoucherait inéluctablement de la Kallipolis. Notre souhait, plus modeste, était de mettre en garde Thomas More contre deux écueils auxquels n'échappe pas la citation exposée au début de ce paragraphe. Ces deux dangers, pointés par Hannah Arendt, sont intimement liés: la primauté de la contemplation sur l'action et la répartition inégalitaire du savoir livresque. L'utopie des livres, pour ne pas se retourner en dystopie, doit prendre conscience de ces travers.

61 Ainsi définie la notion d'éveil utopique, nous sommes en mesure de la confronter à la désobéissance civile.

\section{Le satyagraha ou l'éveil des consciences par la souffrance innocente}

62 Nombre d'exégètes de la philosophie politique gandhienne identifient sans nuance la désobéissance civile à la notion de satyagraha. La confusion provient de Gandhi lui-même, qui utilise parfois indistinctement les termes de "satyagraha » et de "désobéissance civile» pour désigner des moyens de résistance aux ordres ou aux lois injustes d'un Etat. Mais cette assimilation est trompeuse. En réalité, Gandhi définit la désobéissance civile comme une sous-partie du satyagraha : «La non-coopération et la désobéissance civile ne sont que des ramifications différentes de l'arbre appelé satyagraha $»^{86}$. La désobéissance civile est ainsi une forme particulière du satyagraha mais n'en constitue pas toutes ses manifestations, car le satyagraha peut aussi prendre la forme d'une grève, d'un boycott, d'une marche, etc. Ainsi, la désobéissance, en tant que sous-catégorie subsumée dans la catégorie plus large de satyagraha, se voit affectée des mêmes caractéristiques que ce dernier. Si nous parvenons à montrer que le satyagraha constitue une technique d'éveil qui vise à sortir les consciences endormies de leur sommeil complice -, nous l'aurons $a$ fortiori démontré pour la désobéissance civile.

63 Le satyagraha joue le jeu dialogique de la démocratie: son objectif principal est de convaincre l'adversaire politique et non de le contraindre. Il est immoral de chercher à résoudre un conflit par la force physique. Gandhi l'a toujours répété, «l'objectif du satyagrahi consiste à convertir, non à contraindre, celui qui fait le mal $\aleph^{87}$. Mais l'expérience a enseigné à Gandhi que la persuasion par la raison échoue souvent. Nous pouvons le constater au quotidien. Dans ces conditions, comment convaincre l'adversaire politique qu'il est dans l'erreur? Quand l'appel à la raison échoue, quel autre mécanisme permet la persuasion? Gandhi répond : «l'appel au cœur». «Pour obtenir un résultat décisif, explique-t-il, il ne suffit pas de convaincre la raison; il faut également toucher le cœur $»^{88}$. L'appel au cœur fonctionne comme une alternative ou un pas supplémentaire à celui de l'appel à la raison. Quand la tentative de persuasion par le discours rationnel a échouée, les opposants peuvent tenter d'utiliser des moyens de persuasion nonrationnels.

64 Il en découle la question suivante : comment l'appel au cœur peut convertir celui qui est dans l'erreur alors même que la raison a échoué? Par la souffrance personnelle que s'inflige l'innocent, répond Gandhi. En acceptant volontairement de souffrir pour sa 
position morale, le satyagrahi démontre sa force de conviction et dépasse le simple seuil du discours rationnel, qui n'exige aucun courage particulier ${ }^{89}$. Il faut se sacrifier soimême pour toucher le cœur de l'adversaire et éveiller sa conscience endormie. Selon Gandhi, à celui qui me frappe je dois, comme Jésus l'a enseigné, tendre l'autre joue. Il se peut, explique Jean-Marie Muller, "que le fait de refuser d'imiter la violence de l'adversaire le surprenne, alors qu'il pensait mériter une réplique, le décontenance, le déconcerte, et finalement le désarme $»^{90}$. Car, note Gandhi, « il n'y a pas de satisfaction à tuer celui qui fait bon accueil à la mort et c'est pourquoi les soldats aiment attaquer l'ennemi lorsqu'il répond aux coups par des coups et à la violence par la violence ${ }^{91}$. Il ajoute: "Je cherche à émousser complètement l'épée du tyran, non pas en le heurtant avec un acier mieux effilé, mais en trompant son attente de me voir lui offrir une résistance physique. Il trouvera chez moi une résistance de l'âme qui échappera à son étreinte. Cette résistance d'abord l'aveuglera et ensuite l'obligera à s'incliner $»^{92}$. Celui qui fait le sacrifice de soi désarme ainsi toute hostilité. La souffrance a le pouvoir de convertir les raisons les plus sourdes et les cœurs les plus endurcis ${ }^{93}$.

En l'analysant de près, nous comprenons donc que le satyagraha repose sur la croyance implicite en la " bonté de la nature humaine $"^{94}$. Même un Néron a du cœur. Comme le dit Kant, le pire des criminels, parce qu'il est et demeure un être humain, « ne peut jamais perdre toute disposition au bien $»^{95}$. C'est pourquoi il reste toujours au fond de son cœur une petite lueur de bonté que le satyagrahi tente de rallumer/réveiller par sa souffrance innocente. Et, affirme Gandhi à ses disciples, si nous échouions à éveiller la sympathie du tyran et à le convertir à la non-violence, « ce serait de toute évidence que nous n'aurions pas assez souffert $\aleph^{96}$.

Nous pensons avoir correctement démontré la capacité d'éveil du satyagraha. Mais cet éveil satyagrahique est-il forcément utopique? Rien, a priori, ne nous permet de l'affirmer. A bien y regarder, le satyagraha et l'utopie ne s'adressent pas aux mêmes facultés mentales de l'homme. En effet, l'éveil produit par le satyagraha est un éveil des consciences, à la différence de l'éveil utopique, qui s'adresse pour sa part à l'imagination et la raison des sujets. Mais dans l'éveil utopique, le rêve et la raison ne sont qu'une médiation vers l'avènement d'une critique de l'ordre établi au nom de la possibilité d'une autre topie. Appelons-en ici à Husserl qui, à travers le concept d'intentionnalité qu'il reprend à Franz Brentano, nous enseigne que la conscience est toujours orientée vis-à-vis d'un objet, quel qu'il soit. Autrement dit, la conscience a nécessairement une visée intentionnelle, elle est « conscience de ... » Or, dans le cas du satyagraha, quel est l'objet visé par la conscience? Cette "conscience de", en l'occurrence, est conscience de la violence de la colonisation indienne et du système de caste. Sa visée est celle d'un monde sans colons ni castes. Ainsi, l'éveil satyagrahique annonce le dépassement de la violence par la non-violence, de la himsa par l'a-himsa ${ }^{97}$, dépassement de la topie par l'u-topie. En conséquence, le satyagraha - bien qu'il s'adresse aux consciences plutôt qu'à l'imagination et à la raison - est un éveil de nature pleinement utopique. Cela vaut aussi pour la désobéissance civile, en tant qu'elle est une forme particulière du satyagraha.

Ainsi, qu'on la conçoive comme modalité de la conversion utopique ou plus simplement comme arme de l'utopie, la désobéissance civile semble aujourd'hui constitutive de la marche de l'utopie. A une époque où la chute de l'Union soviétique a sonné le glas de l'utopie communiste, et où l'éclatement du mouvement altermondialiste ne fournit pas de projet politique alternatif suffisamment consistant, il est salutaire d'apprendre, en 
prolongeant la pensée abensourienne, que la désobéissance civile et la non-violence peuvent constituer des voies innovantes vers l'altérité sociale absolue.

\section{NOTES}

1. L'intérêt d'un penseur réside selon nous moins dans ce qu'il nous dit explicitement que dans ce que ses écrits nous permettent de penser. Ainsi, nous souhaitons prolonger la pensée d'Abensour en lui faisant aborder une question à laquelle l'auteur ne consacre pas la moindre ligne de son œuvre: la désobéissance civile. Nous faisons l'hypothèse que cette exploration abensourienne de la désobéissance civile aura le mérite de révéler les potentialités utopiques de cette dernière.

2. GUERIN, Daniel, L'anarchisme, Gallimard, 1981, Paris, p. 59. Prenant le contrepied de Guérin, Eduardo Colombo a mis en évidence la «fonction utopique » des révolutions anarchistes qui, en tant que rupture et opposition à l'ordre dominant, dessinent une image d'altérité de tout ce qui est au profit de tout ce qui peut être. In COLOMBO, Eduardo, L'espace politique de l'anarchie: Esquisses pour une philosophie politique de l'anarchie, Atelier de création libertaire, Lyon, 2008, p. 156 3. Année de soutenance de sa thèse d'Etat, Les Formes de l'utopie socialiste-communiste: essai sur le communisme critique et l'utopie, sous la dir. de Charles Eisenmann et Gilles Deleuze

4. ABENSOUR, Miguel, L'homme est un animal utopique, p. 93

5. Ibid.

6. Ibid., p. 8

7. Ibid., p. 199

8. Ibid., p. 212

9. Ibid., p. 203

10. Dont les initiateurs seraient Charles Fourier et William Morris.

11. Ibid., p. 215

12. Ibid., p. 209

13. Ibid., p. 12

14. Voir ABENSOUR, Miguel, « La conversion utopique : L'utopie et l'éveil », op. cit., pp. 7-52

15. LA BOETIE, Etienne, Le discours de la servitude volontaire, Paris, Petite Bibliothèque Payot, 2002, p. 128

16. WEIL, Simone, "Méditation sur l'obéissance et la liberté », in LA BOETIE, Le discours de la servitude volontaire, p. 113

17. GANDHI, Résistance non violente, Paris, Buchet-Chastel, 2007, p. 209

18. « La liberté est naturelle », écrit La Boétie, op. cit. p. 142

19. Voir le commentaire de LAMENNAIS, in LA BOETIE, op. cit. p. 47. Il liste quatre instruments d'assujettissement du peuple par le tyran, que La Boétie lui-même dévoile de façon éparpillée dans la première moitié du Discours.

20. ABENSOUR, Miguel, « Les leçons de la servitude et leur destin », in LA BOETIE, op. cit. p. 70

21. LA BOETIE, op. cit. p. 134.

22. Loc. cit.

23. BELLEGARRIGUE, Anselme, cité in BEKAERT, Xavier, Anarchisme, violence, non-violence, Paris, Editions du Monde Libertaire, 2000, p. 65 
24. BOUKOVSKY, Vladimir, Et le vent reprend ses tours : Ma vie de dissident, Paris, Robert Lafon, 1978, p. 35

25. GOYARD-FABRE, Simone, in La Boétie, Discours de la servitude volontaire, Paris, Flammarion, 1993, p. 80

26. GANDHI, Tous les hommes sont frères, p. 247

27. Loc. cit.

28. CLASTRES, Pierre, « Liberté, Malencontre, Innommable », in LA BOETIE, Discours, Payot, p. 266

29. Loc. cit.

30. LA BOETIE, op. cit. p. 139.

31. Ibid. p. 155. « Estre franc » signifie « être libre».

32. GANDHI, op. cit. p. 247

33. Ibid. p. 250

34. LA BOETIE, op. cit. p. 202

35. THOREAU, La désobéissance civile, p. 39

36. Ibid. p. 40

37. Nous ne sommes cependant pas certains que l'expression soit de Thoreau. Lors de sa première publication, le texte est intitulé « Résistance au gouvernement civil ». C'est en 1866, à l'occasion d'une réédition posthume, que l'éditeur nomme le texte "désobéissance civile». L'expression proviendrait de la correspondance de Thoreau.

38. GANDHI, Révolution non violente, Paris, Buchet/Chastel, 2007, p. 102

39. THOREAU, op. cit. p. 39

40. PEDRETTI, Mario, La figure du désobéissant en politique, Paris, L'Harmattan, 2001, p. 56

41. GANDHI, Résistance non-violente, Paris, Buchet/Chastel, 2007, p. 387

42. Le "peuple" est évoqué dix-neuf fois dans le Discours. Et à plusieurs reprises La Boétie s'adresse directement à lui, par l'usage du vouvoiement. Claude Lefort étudie les variations du discours laboétien dans « Le nom d'Un », in LA BOETIE, Le discours de la servitude volontaire, p. 269 et ss

43. LA BOETIE, ibid. p. 134

44. ABENSOUR, Miguel, «Du bon usage de la servitude volontaire? », Réfractions, $\mathrm{n}^{\circ} 17$, hiver 2007 , p. 83

45. MARKOVITS, Claude, Gandhi, Paris, Presses de Sciences Po, 2000, p. 149

46. Loc. cit.

47. Première formation politique indienne, créé en 1885 , et n'ayant à l'époque aucune revendication indépendantiste.

48. GANDHI, op. cit. p. 240

49. Loc. cit.

50. KING, op. cit. p. 49

51. KING, cité in MOLLA, Serge, Les idées noires de Martin Luther King, Paris, Labor et Fides, 2008, p. 202

52. LA BOETIE, op. cit. p. 172

53. Ibid. p. 232

54. Ibid.p. 180

55. La Boétie remarque que les tyrans sont souvent tués par leurs favoris, qui vivent dans la crainte permanente de leur maître.

56. La Boétie, comme Socrate dans le Gorgias, semble donc suggérer qu'un tyran ne peut pas être heureux, qu'un être immoral ne peut pas connaître le bonheur. Kant, plus tard, défendra l'idée inverse. Il existe des criminels et des tyrans heureux. Les philosophes ont fait une fausse promesse en expliquant que l'accès au bonheur n'était accessible qu'à travers la moralité. Ce qui est vrai, en revanche, c'est que seule la moralité rend digne d'être heureux, et permet un bonheur sans remord. 
57. Gandhi vise le système de la colonisation, King celui de la ségrégation et Thoreau celui de l'esclavage. Mais nous verrons plus loin qu'ils considèrent de nombreuses autres organisations sociales comme des systèmes pervers (la technique moderne, l'automation, le capitalisme, le communisme, l'impérialisme, la civilisation occidentale, le machinisme, le matérialisme, etc.).

58. Il faut ainsi concevoir le social du point de vue d'un structuralisme constructiviste ou d'un constructivisme structuraliste.

59. KING, op. cit. p. 48

60. GANDHI, op. cit. p. 231

61. Ibid. p. 59

62. KING, cité in MOLLA p. 47

63. KING, Révolution non violente, p. 199

64. Loc. cit.

65. NANDY, Ashish, «Oppression and human liberation: Towards a Third World Utopia ", Alternatives, IV, octobre 1978, p. 172

66. DE LIGHT, Barthélémy, Pour vaincre sans violence, Paris, G. Mignolet et Storz, 1935, p. 127

67. CLASTRES, Pierre, "Le retour des Lumières", in Revue française de science politique, 1977, volume $27, \mathrm{n}^{\circ} 1$, pp. 22-29

68. Voir le commentaire de LAMENNAIS, p. 47 de l'édition Payot. Il liste ces quatre instruments d'assujetissement du peuple par le tyran, que La Boétie lui-même dévoile de façon éparpillée dans la première moitié du Discours.

69. LA BOETIE, Ibid., p. 155.

70. Ibid., p. 144. En français moderne, dans la traduction de Charles Teste: "Quel malheureux vice (=malencontre) a donc pu tellement dénaturer l'homme, seul vraiment né pour vivre libre, jusqu'à lui faire perdre la souvenance de son premier état et le désir même de le reprendre ? ».

71. Il faut ici introduire une distinction entre deux «natures», dont La Boétie parle indistinctement. D'une part, la «nature humaine» ou nature de l'homme, selon laquelle l'homme est naturellement libre. D'autre part, la « nature des choses » ou nature cosmologique. Cette seconde nature est, chez La Boétie comme chez Aristote qu'il a longuement lu et étudié, téléologique. Cette distinction est importante, mais elle importe peu pour notre sujet puisque, dans le Discours, ces deux natures conduisent à la même destination : le régime politique du Tous uns.

72. Mais cet idéalisme naïf serait tout simplement une falsification historique. Pour une critique interne (c'est-à-dire libertaire mais lucide) de la Catalogne libertaire, on pourra par exemple se référer aux écrits de Simone Weil qui, pour être allée apporter son soutien sur place, a pu témoigner des dérives autoritaires de la direction anarchiste de la Généralité. In WEIL, Simone, Ecrits historiques et politiques, pp. 218-219

73. D'où la nécessité «d'une nouvelle idée de l'homme, d'une nouvelle anthropologie », écrit Pierre Clastres. La Boétie anticipe de trois siècles l'anthropologie de l'homme moderne : homme dans l'état d'aliénation (chez Marx), de déchéance (chez Nitetzsche), de servitude.

74. CLASTRES, Pierre, «Liberté, Malencontre, Innomable ", in Le discours de la servitude volontaire, Petite Bibliothèque Payot, Paris, 2002, p. 249

75. Ce passage par la logique et les équations peut sembler cavalier. Nous aurions pu nous abstenir de ce langage formel et nous contenter d'une écriture exclusivement littéraire et prosaïque. Cela n'aurait strictement rien modifié au contenu de notre démonstration, mais la présentation en aurait été alourdie et la lecture rendue plus laborieuse. Ainsi, notre choix résulte d'un simple souci de clarté et de compréhension.

76. ABENSOUR, op. cit., p. 18

77. Nous faisons ici référence à la sentence par laquelle François Furet achève Le passé d'une illusion : « Nous voici condamnés à vivre dans le monde où nous vivons ». 
78. Walter Benjamin fut le premier à théoriser ce pouvoir, dans Paris, capitale du XIXé siècle, Paris, Cerf, 2000

79. Nous reprenons ici cette expression de Noam Chomsky par laquelle il désigne les stratégies de manipulation de masses des médias capitalistes en vue de produire du consentement.

80. L'éveil utopique s'inscrit ainsi dans une temporalité de la césure, de l'entre-deux ou de ce que Martin Breaugh nomme une temporalité de la «brèche ». Cf BREAUGH, Martin, L'expérience plébéienne, Paris, Payot, 2007

81. Pour clarifier son idée, il ajoute que « là où l'imagination dépasse la rêverie ou le délire, et aboutit à des résultats durables, c'est parce qu'elle constitue de nouvelles formes universelles ; là où la rationalité est raison créatrice et non répétition vide, c'est parce qu'elle se nourrit à des sources imaginaires dont aucune pseudo-rationalité «scientifique » ne peut rendre compte ». In CASTORIADIS, Cornelius, "La révolution anticipée ", in Mai 68 : La Brèche, suivi de Vingt ans après, Paris, Fayard, 2008, p. 138

82. ABENSOUR, op. cit., p. 50

83. Abensour a justement pour habitude de faire jouer un auteur (Marx, Saint Just) contre luimême.

84. BREAUGH, Martin, "Le lien social entre utopie et démocratie", ain Critique de la politique. Autour de Miguel Abensour, dir. KUPIEC, Anne, TASSIN, Etienne, Sens\&Tonka, Paris, 2006, p. 88

85. MORE, Thomas, L'utopie, Bruxelles, La Renaissance du livre, 1966, p. 67

86. GANDHI, Résistance non-violente, p. 273

87. GANDHI, cité in LASSIER, p. 140

88. GANDHI, Tous les hommes sont frères, p. 162

89. Il est utile de rappeler les mots sévères d'Arendt contre cette idée de Gandhi que le sacrifice de soi est une preuve de la force de notre conviction : « Il est regrettable que tant de personnes soient persuadées que la «volonté de se sacrifier soi-même » constitue la meilleure preuve de «l'intensité de l'engagement » et du sérieux de «celui qui désobéit par fidélité à une loi », car cette forme de fanatisme uniquement tendue vers son objectif est en général le fait d'excentriques et, de toute façon, a pour effet de rendre impossible une discussion rationnelle des données du problème ». In "La désobéissance civile», Du mensonge à la violence, Paris, Calmann-Lévy, 1972, p. 69

90. MULLER, Gandhi, pp. 33-34

91. GANDHI, cité in MULLER, Gandhi, p. 34

92. GANDHI, Lettre à l'ashram, Paris, Albin Michel, 1960, p. 110

93. Bakounine pensait par ailleurs qu'il valait mieux faire appel à la conscience de l'individu qu'à sa raison. Car la raison peut devenir un obstacle à l'action : elle entraîne la division interne et l'inhabilité à agir. L'analyse rationnelle, parce qu'elle est sans fin, paralyse l'action. La conscience, au contraire, se préoccupe davantage de mener une action efficace que d'atteindre une pensée pure.

94. GANDHI, Résistance non-violente, p. 140

95. KANT, Emmanuel, Métaphysique des mœurs, Paris, GF-Flammarion, 1994, p. 334

96. GANDHI, cité in LASSIER, op. cit. p. 41

97. Etymologiquement, le terme " ahimsa », c'est-à-dire « non-violence », se compose du préfixe privatif « a » et du substantif « himsa », qui veut dire « violence » en Indien. 


\section{AUTEUR}

MANUEL CERVERA-MARZAL

Diplômé de Sciences-Po Paris et du Master « Sociologie et Philosophie politique » de l'Université Paris-Diderot. Travaille sur la désobéissance civile et l'action directe non-violente. Doctorant en co-tutelle à l'Université Libre de Bruxelles (sous la direction de Justine Lacroix) et à l'Université Paris-Diderot (sous la direction d'Etienne Tassin). 